\title{
Regional approaches to solving the problems of inclusive education
}

\author{
Irina Usova ${ }^{1,{ }^{*}, \text { Ludmila Demyanova }}{ }^{2}$, Natalia Kochkovaya ${ }^{1}, \mathrm{Ol}^{\prime}$ ga Mavropulo $^{2}$, and Igor \\ Stolyar ${ }^{1}$ \\ ${ }^{1}$ Institute of Technologies (branch) of DSTU in Volgodonsk, Mira avenue, 347386, 16, Volgodonsk, \\ Rostov region, Russia \\ ${ }^{2}$ Don State Technical University, 344003, Gagarin Square, 1, Rostov-on-Don, Rostov region, Russia
}

\begin{abstract}
The article deals with the integration processes in the Russian education system. In recent years, they have become increasingly active in the practice of education and become a reality. It is important to emphasize the relative novelty of this component in the domestic education system. And since we are only taking the first steps in this direction, then inevitably questions arise about the ways, means and possibilities of solving this problem in the existing socio-economic and socio-cultural conditions that have developed in modern Russian society.
\end{abstract}

\section{Introduction}

In the 90s of the last century, the Ministry of Education of the Russian Federation quite clearly defined its position of supporting the process of including children with various developmental disabilities into the environment of normally developing peers, thereby legalizing integration trends, as it were. Moreover, the subjects of the Federation were urged to act more boldly in this direction [1].

On the other hand, the regions had to independently seek and find opportunities for integrated education and upbringing of children with special educational needs due to quite objective reasons, one of which was a new social order coming from the parents of the children.

\section{The peculiarities of integration process in education system in Russia}

The main ideas reflecting the strategic line of integration processes, were as follows:

- The development of the idea of integration as one of the leading trends of the modern stage in the development of the domestic system of special education does not mean in any way the need to curtail the system of differentiated education for different categories of

*Corresponding author : irina_usova@mail.ru 
children. A well-thought-out state policy is important, which does not allow "distortions" and «excesses», a balanced combination of the principles of integration and professional influence in specially organized conditions [2].

-Every person regardless of health status physical or mental disability, has the right to receive education, the quality of which does not differ from the quality obtained by healthy people.

- The most important developmental periods for children with disabilities are infancy, early and preschool ages. These periods in the life of children with disabilities require increased attention from the state and society.

- Medical, social and educational institutions provide parents with full information.

-Work with the family begins from the moment a child is found to have a particular physical or intellectual impairment. Experts involve parents as full-fledged partners in compiling an individual program of habilitation and rehabilitation [3]. The role of parents is changing qualitatively: they are included in the life of the children's collective, the collective of teachers and parents.

- From an early age, the specialist helps parents to include children with mental and physical disabilities in the communication space of healthy children.

- At the request of parents, children with mental and physical disabilities are included in educational institutions at their place of residence, parents have the right to attend all classes of specialists.

- One of the ways to establish a qualitatively new interaction between special and mass education is the creation and development of fundamentally new educational institutions institutions of a combined type, including preschool groups or classes for both normally developing children and children with a certain developmental disability [4].

- Each child should be given the right to develop at their own personal pace.

-Effective integrated education is possible only on condition of special training and retraining of personnel, both teachers of general education and special (correctional) institutions.

- Taking into account the novelty, social significance, complexity, complexity of the problems solved in the framework of integrated education, it is necessary to provide for fundamental and applied scientific research of an interdisciplinary nature.

One of the directions of the developed strategy provided for the creation of experimental sites that would allow both teachers and educational organizers to accumulate a methodological base for integrated learning and gain experience in new conditions, as well as test variable integration models. There are three main forms of children education in Russia (Fig.1).

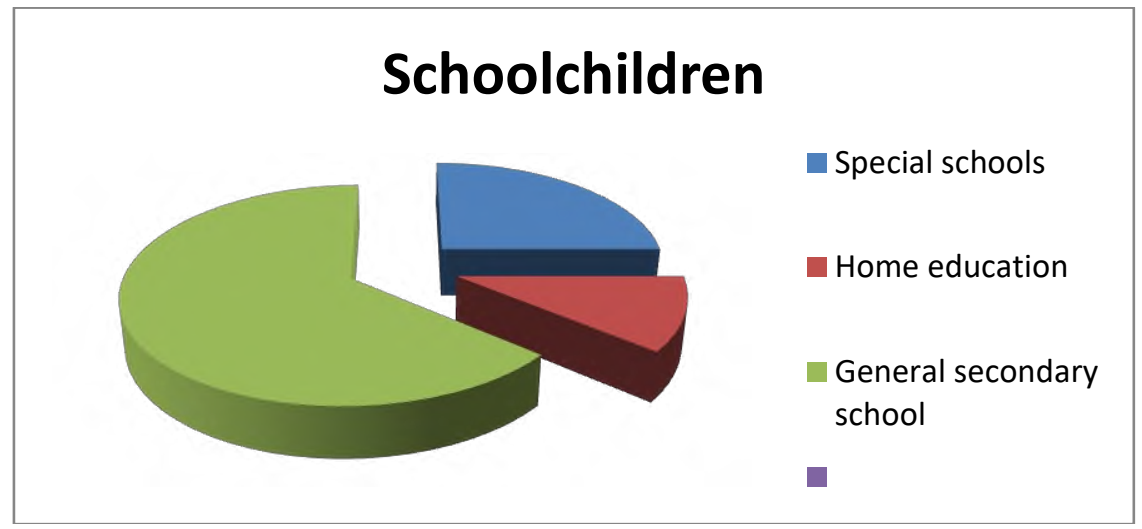


Fig. 1. Main forms of children education in Russia

The nosology groups are shown in Fig.2.

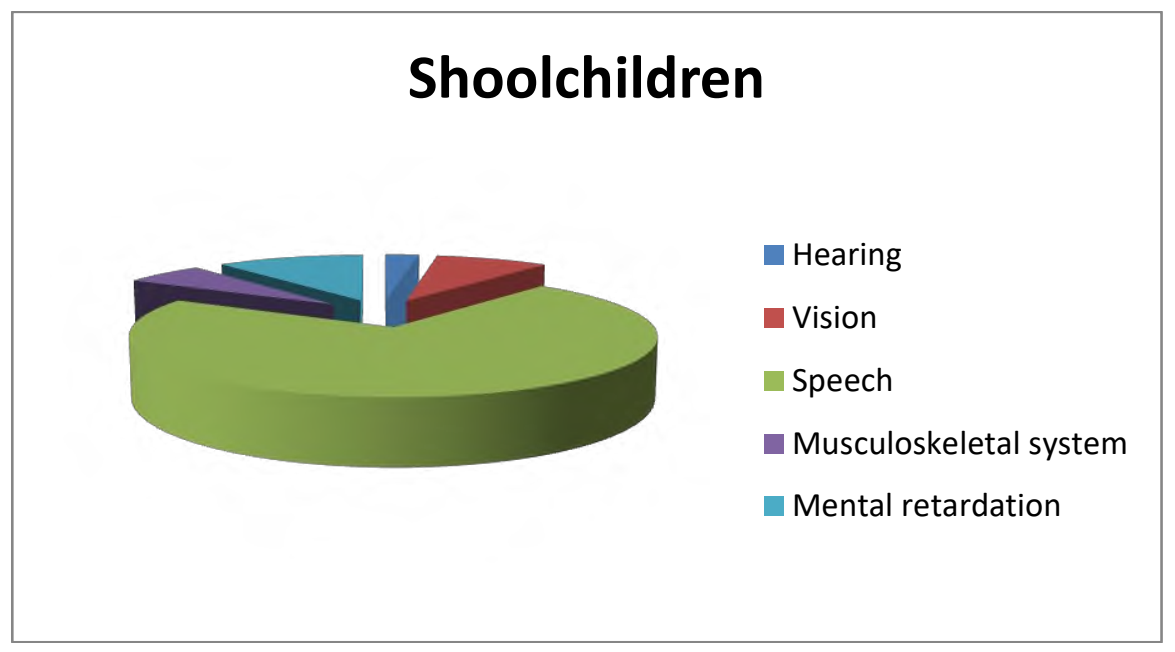

Fig. 2. Nosology groups

Today we all quite clearly imagine that the integration processes are conditioned by the socio-political changes taking place in our society [5]. The need to provide all children with equal rights to receive educational services, regardless of the state of their mental and physical health, is increasingly recognized not only in the field of special education, but also by teachers of mass preschool and school educational institutions .

Looking ahead also fosters awareness of the inevitability and necessity of developing inclusive education. An analysis of the health status of children in Russia suggests that the number of children with "special educational needs" is unlikely to decrease in the near future, but rather the opposite. And if all these children join the system of differentiated education, then in the system itself such a large-scale differentiation can give rise to a critical situation. Therefore, many children, especially children with mild developmental disabilities, will inevitably be accepted by mass kindergartens and schools.

Building the educational process in the context of inclusive education requires a verified, scientifically grounded approach that would absorb all the available both foreign and domestic experience of integrated education. In addition, it should be noted the importance of a flexible approach to the development of integration processes. It is hard to imagine that without creative processing of existing models of integrated learning (domestic and foreign), they are with the same will function successfully in various socioeconomic and socio-cultural conditions.

As for the foreign experience of integration, in each country this experience has its own both historical and socio-cultural roots. If we talk, for example, about the Norwegian model of integrated education, then despite the fact that integration in Norway has a state legislative basis, it cannot be said that the practice of raising and educating children with special educational qualifications does not experience any serious problems there. The experience of professional communication with Norwegian specialists allows us to say that quite often integration is of a formal nature and children with developmental disabilities, being within the confines of a mass school, are no less isolated than before. As a rule, models of partial or temporary integration are used more often. As for full integration (and such a variant of integration takes place, although it is far from being represented everywhere), in this case everything depends on the ability of an ordinary teacher and a special teacher to build their professional relationships and organize joint work. Sometimes 
the teacher working with the class can simply ignore both the special teacher and his recommendations, and also be indifferent to the special child included in his class [6]. As for the passive stay of a child with special educational needs in a regular classroom (which, as a rule, amounts to including him in the educational process), it can hardly be considered sufficiently productive in terms of the effect of correctional and developmental education. Although, at the same time, there is no point in denying the humanistic value of such inclusion and the importance of communication between the "special" child and normally developing peers, as well as the possibility and importance of the awareness of normally developing children that children can be different and have different learning opportunities. It should also be noted the humanistic value of the attitude that Norwegian teachers often demonstrate in interaction with their pupils. This model of interaction, imbued with love for the child, demonstrating its complete acceptance, deserves special attention.

As for the construction of models of integration in the Russian education system, in this case, the path associated with the parallel study of not only foreign and domestic, but also regional experience seems to be more promising. It would be more correct to speak about the need to develop regional concepts of inclusive education or to include children with disabilities in the educational space of the region.

The experience of social and educational integration in the Rostov region shows that the regional education system implements and tests various integration models, although many of them do not have the status of experimental and experimental, and sometimes arise spontaneously [7].

The existing spectrum of integration models can be presented hierarchically from wellknown, scientifically and methodologically verified and substantiated to single and specifically regional ones. The emergence of the latter is due to the special conditions prevailing in one of the other settlements of the region, and can be considered as the only possible way out in the specific situation of the regional educational space. However, the experience of such rather forced searches and finds is especially valuable because it has its own regional origins and arises in the very depths of the national education system. Purposeful study and generalization of this experience, of course, could contribute to a more effective development of integration processes on the ground.

The conditions of temporary, partial, combined or full integration that exist in ordinary kindergartens and schools can serve as examples of well-known models for the inclusion of children with special educational needs in the educational space of the region [8]. Many educational institutions have accumulated more than ten years of experience, proving the effectiveness of an inclusive approach to teaching and raising children with disabilities. At the same time, in most cases it is not about educational, but rather about social integration. In addition, these models are presented mainly in large settlements of the region.

As for rural areas, practice shows that in a number of cases, teachers of rural correctional schools and orphanages successfully carry out the social integration of their pupils. For example, mentally retarded schoolchildren are included in amateur art circles, in which they study together with students of public schools, and then give concerts in front of residents of villages and villages. According to the observations of teachers, such cooperation has a positive effect not only on the pupils of the correctional school. Pupils of the mass school in the process of communication, cooperation and co-creation with mentally retarded schoolchildren go through a special school of personal growth, assert themselves, helping the weaker ones, learn to be attentive, patient, caring, at the same time becoming teachers' assistants [9].

Of particular interest are examples of educational integration that emerged due to emergency situations in the educational space of a particular settlement.

It makes sense to give several typical examples that demonstrate how this problem is solved in the real conditions of the regional education system. Several years ago, at the 
Center for Psychological, Pedagogical and Medical and Social Assistance of the Pomor State University named after M.V. Lomonosov, the parents of a thirteen-year-old girl with Down syndrome from the Pomor village of Nizhnyaya Zolotitsa applied. The girl studied from the age of eight in a local small-scale mass school according to an individual program in a class of different ages for five years, being constantly present at all lessons. All the specialists of the center noted the high level of her socialization: the girl communicated with desire, noted that she loved Russian, reading, drawing more than other subjects. He is happy if he gets "five" or "four", he gets upset if he gets "three".

In the successes achieved in the girl's schooling, a decisive role was played by the wellcoordinated interaction of her parents and school teachers, who professionally solved the issue of organizing psychological and pedagogical support for the child in the process of passing the individual educational route [10].

Then a seven-year-old boy came to the first consultation. The village where the family lived was located 80 kilometers from the district center. The boy's parents had higher education, his grandmother was a kindergarten teacher in the past. The family members had a great desire to help the child, but they lacked the knowledge and practical skills to provide adequate assistance in learning. The boy did not speak, he had a pronounced mental retardation. Grandmother gave all her strength to the organization of speech therapy classes, which for the most part were reduced to the setting of sounds, while being guided by purchased textbooks on speech therapy. All this complicated the child's developmental situation for the second time.

The regional psychological and pedagogical commission, taking into account the desire of the parents, sent the child to study at the place of residence. Local education authorities met halfway and made it possible to study according to an individual program in a local rural mass school. At the same time, the grandmother became the first teacher for the boy. Other teachers, having no experience of teaching such children, at first did not challenge her this right. The boy studied for two years under the first grade program, then for one year under the second grade. Now he is being taught by mass school teachers. The boy is calm and flexible, easily builds relationships with peers and adults, this allows him to be present at school almost all the time. In addition, for several years the family has been constantly provided with advice by the specialists of the center.

The last consultation at the center, to which the family once again came, showed that the boy has achieved a good level of social adaptation, he feels much more confident in a situation of interaction in an unfamiliar environment, he says, reads, writes. But most importantly, during this time in the family, he acquired everyday and practical skills, which to a large extent provided him with a sense of self-confidence. Great changes took place in the mood of the boy's mother, her level of anxiety decreased, she became calmer and more confident in the future of her family and child [11].

It should be noted that such an approach to solving the problem of education of children with special educational needs can be implemented only if there are two factors: the desire of the parents and the ability of teachers to carry out inclusive education. In this case, not only the child, who begins to feel self-sufficient and protected, is the winner, but also the family, in which peace and confidence in the future is restored to a certain extent.

In general in recent years the issues of including children. Living in the districts of the region, the mass educational environment began to be resolved more successfully. Educational authorities grant such a child the right to individual education in a mass school at the place of residence [12]. However, it must be emphasized that one referral to a mass school is not always enough for a child to be accepted, so that a teacher in a mass school will accept his special educational needs. Therefore, in the fact that the processes of "inclusion" are successful in such cases, great credit goes to local teachers who reveal tendencies of selflessness, and without special training, often only on the basis of 
pedagogical intuition, self-education and love for the child, its content adequate to the child's capabilities.

Every year the increasing number of examples of regional integration processes testifies to the fact that integration is becoming more and more familiar, and, most importantly, a component of a single organism of the regional educational system accepted by teachers by society [13]. The grains of integration experience accumulated in the region require deeper understanding and generalization, selection of its positive links, which can allow avoiding mistakes in the future and prepare the development of the most acceptable regional models of social and educational integration [14]. The purpose of this work is to determine the optimal forms and content of education and training that would allow any child with special educational needs to join society at the level of his psychophysical capabilities and achieve his functional norm.

\section{Conclusion}

With this approach the main goal of the integration processes is achieved which is their humanistic orientation. The principle of variability in the creation and implementation of regional models of integration, taking into account specific socio-economic and sociocultural conditions, presupposes the possibility of realizing the right of every child to receive an education and contributes to the real awareness of the value of any child by society [15]. The upbringing and educational process in this case, both in organizational terms and in content, can most closely approach the individual educational needs and capabilities of students, and will be less subject to unification. At the same time, the implementation of regional integration models is possible only if there is an appropriate legislative framework and the professional readiness of teachers of mass and special educational institutions to work in new conditions.

\section{References}

1. E. A. Irtuganova, I. G. Filimoncheva, From the experience of inclusive education organizing in Kazan National Research Technical University named after A. N. Tupolev, 2(10), 20-33 (2018)

2. O. V. Kuchmaeva, Education of disabled children the statistical aspect, Statistics and economics, 6, 19-24 (2016)

3. I. A. Makarova, Tolerance in inclusion: the philosophical approach, Topical issues of social Sciences: sociology, political science, philosophy, history: collection of articles on materials of XXIX international scientific and practical conference, 9(29) (2013)

4. O. A. Gurkina, E. M. Novikova, Modern Foreign Psychology, 1, 6-15 (2014)

5. O. A. Denisova, O. L. Lehanova, University as a resource educational and methodological center for the region in the space of inclusive education, Special Education, 1, 8-11 (2017)

6. I. Ju. Frolova, Inclusive education in Russia: problems and perspectives, Pedagogical Sciences, Scientific notes of Orel State University, 3(76), 347-350 (2017)

7. S. V. Matveeva, I. A. Bukina, Special Education, 1, 130-133 (2017)

8. A. A. Kiselyova, Features of coping strategies in persons with disabilities, ACTA SCIENTIFICA, 5(1), 129-133 (2017)

9. T. Bomana, Employment opportunities for persons with different types of disability, ALTER, European journal of disability research, 1, 62-64 (2015) 
10. A. C. Manolachea, Development of disabled employees from academic environment, Social and Behavioral Sciences, I. 142, 71-77 (2014)

11. V. Friso, Capability, work and social inclusion, I. 116, 4914-4918 (2014)

12. E. Tyan, Inclusive potential of continuing education, Inclusive education, 163-169 (2015)

13. V. G. Goncharova, Integrated medical-psychological-pedagogical accompaniment of persons with disabilities in conditions continuous inclusive education, Siberian Federal University 248 (2014)

14. A. Galiev, A. F. Shigabutdinova, L. G. Gubaidullina, From the experience of volunteer students with children and youth with disabled health opportunities, Inclusion in education, 1(9), 37-46 (2018)

15. E. Agafonova, Towards acceptance: psychological support for parents children with disabilities, Inclusive education, 169-175 (2015) 